\title{
LAS ÚLTIMAS GIRAS DE LOS BAILES RUSOS DE DIAGHILEV EN ESPAÑA: BARCELONA (1924- 1927)*
}

\section{THE LAST TOURS OF DIAGHILEV'S RUSSIAN DANCES IN SPAIN: BARCELONA (1924-1927)}

\author{
Pedro Castillo Palomares \\ Doctor en Historia
}

\section{RESUMEN}

El presente trabajo analiza la cobertura mediática de la prensa publicada en Barcelona en los años que van de 1924 a 1927 del espectáculos de los bailes rusos del empresario Sergue Diaghilev y su reaparición en el Gran Teatre del Liceu desde su última actuación en el año 1918. Se describen las sesiones y la composición de los programas de los días de actuación junto con las impresiones de la crítica teatral sobre las representaciones de los ballets russes.

Palabras clave: Sergue Diaghilev, ballets russes, Liceu, Artes Escénicas, Historia de la Cultura.

\section{ABSTRACT}

The present work analyses the media coverage in the press published in Barcelona during the period from 1924 to 1927 regarding the Russian dance shows organised by the businessman Sergue Diaghilev and its reappearance in the Gran Teatre del Liceu since the last performance in 1918. The sessions are described, as is the composition of the programmes of the performances and the impressions of the theatrical reviews of the ballets russes productions.

Keywords: Sergue Diaghilev, ballets russes, Liceu, Performing Arts, History of Culture.

* El presente artículo es una ampliación los puntos 3 y 4 del capítulo 4 de la Tesis doctoral defendida en el año 2017, Crónicas españolas de los bailes rusos de Diaghilev (1916-1927), y que inexorablemente mantiene la estructura del calendario de los días de sesiones correspondientes a las programaciones de la compañía de Diaghilev en el Gran Teatro del Liceo los años 1924, 1925 y 1927. Desde el respeto a las fuentes y a la ética científica se ha visto la necesidad de presentar esta propuesta complementaria con material inédito no publicado para ampliar y entender mejor la acogida de compañía rusa por parte de la crítica de espectáculos de la prensa de Barcelona. 


\section{RESUM \\ LES DARRERES GIRES DELS BALLS RUSSOS DE DIAGHILEV A ESPAÑA: BARCELONA (1924-1927)}

El present treball analitza la cobertura mediàtica de la premsa publicada a Barcelona en els anys que van de 1924 a 1927 de l'espectacle dels balls russos de l' empresari Sergue Diaghilev i la seva reaparició al Gran Teatre del Liceu des de la seva última actuació en l'any 1918. Es descriven les sessions i la composició dels programes dels dies d'actuació juntament amb les impressions de la crítica teatral sobre les representacions dels ballets russes.

Paraules clau: Sergue Diaghilev, ballets russes, Liceu, Arts Escèniques, Història de la Cultura. 
La compañía de ballets russes del empresario Serge Diaghilev a partir de su presentación en Paris en mayo de 1908 llevó a cabo diferentes giras artísticas por Europa, Estados Unidos y Suramérica durante la segunda y tercera década del siglo XX hasta la muerte de su creador y director el 19 de agosto de 1929. Durante este periodo de tiempo visitaron España en diferen- tes ocasiones entre los años 1916 y 1927.

Las primeras giras españolas fijadas en varios momentos temporales de mayo 1916 a junio 1918 vienen determinadas por la Primera Guerra Mundial, la neutralidad de España en el conflicto y las consecuencias económicas y artísticas que la contienda tiene para el devenir organizativo de la compañía rusa. El proyecto empresarial y artístico de los ballets russes llegó casi a su disolución en el verano de 1918. ' Después de esta gira se descolgaron varios componentes del cuerpo de baile del ya casi insolvente proyecto diaghileviano al finalizar el verano de 1918.como Valentina Kachouba, ${ }^{2}$ Alexander Gavrilow, ${ }^{3}$ Nicola Zverev o Vera Nemtchinova. ${ }^{4}$

1 Diaghilev tras unos años de reajuste organizativo en Londres tras el fin de la Primera Guerra Mundial en los que recuperó la iniciativa empresarial de los ballets russes, las pérdidas materiales y personales sufridas durante 1918, su compañía de bailes rusos afrontó los retos de un renovado mercado escénico surgido a comienzos del periodo de entreguerras en Europa. Al acabar el conflicto bélico la historiadora Lynn Garafola observó la llegada de la paz a Europa trajo consigo una expansión de la danza por el continente con el nacimiento de nuevas compañías de ballets en diferentes países que imitaban al estética de los bailes rusos y que empezaron a disputarle el protagonismo a Diaghilev dentro del mercado del espectáculo. En los años previos del armisticio solo Valentina Palvlova había experimentado con producciones entre la ópera y el music-hall, a partir de la década de los veinte surgieron nuevas propuestas escénicas con un reflejo de la concepción diaghileviana del ballet. GARAFOLA, Lynn (1998), pp. 211 y 217.

2 Valentina Kashouba llegó a actuar con una compañía de bailes rusos en el Teatro Lara de Madrid en noviembre de 1921, El Imparcial, 1 de noviembre de 1921, p. 6.

3 Dirigía una troupe de bailes rusos que interpretaban obras del repertorio de Diaghilev como las danzas de "El príncipe Igor". Actuaron a principios de mayo de 1921 en el teatro de La Zarzuela de Madrid, ver La Época, 4 de mayo de 1921, sección espectáculos.

4 Aunque en el caso de estos dos últimos bailarines se reincorporaron más tarde después de actuar con otras compañías por España. 
Las siguientes tournées enmarcadas ya dentro del periodo político y social de entreguerras europeo y de la crisis del sistema de La Restauración en España, se fijan en los años 1921 y 1922 en Madrid y San Sebastián, ${ }^{5}$ respectivamente. $Y$ en último lugar, se sitúan las giras que ponen fin al periplo español de los ballet russes durante los años 1924, 1925 y 1927 en Barcelona, dentro del contexto político de la dictadura de Miguel Primo de Rivera. Sergue Diaghilev y su compañía de bailes rusos desde el año 1918, tras años de ausencias en el escenario del Gran Teatro del Liceo, volvían a la capital catalana cuya oferta del espectáculo se había diversificado desde su última visita.

\section{Año 1924. Estreno de el sombre- RO DE TRES PICOS EN BARCELONA}

Habían pasado casi seis años desde la última actuación de los ballets russes de Diaghilev en Barcelona y la dirección del Liceo a cargo de la empresa de Juan Mestres programó la vuelta de la compañía de danza para el sábado 19 de abril. ${ }^{6}$ Los primeros anuncios de la reaparición de la compañía comenzaron en el mes de marzo con una campaña publicitaria en la prensa de Barcelona coincidiendo con las actuaciones en el teatro situado en Las Ramblas del compositor ruso Igor Stravinsky. ${ }^{7}$ Por ejemplo, el diario La Vanguardia no sólo publicitó a la compañía en la sección de espectáculos, sino también en el apartado de Notas Locales: "En breve los auténticos Bailes Rusos de Serge Diagilew". La principal novedad de las sesiones era la presentación de "El sombrero de tres pi$\cos ^{\prime \prime}$ en Barcelona. ${ }^{8}$ Aunque por su parte el Diario de Barcelona destacara los "cuatro hermosos ballets" programados para la noche del 19 de abril de 1924 y el "aspecto bri-

5 Antes del regreso de los bailes rusos a la capital catalana, en las últimas giras españolas que comprenden los años de 1921 y 1922 Diaghilev había estrenado "El sombrero de tres picos" en Madrid, y los bailes rusos fueron la gran atracción de los actos conmemorativos del IV centenario de la vuelta al mundo de Juan Sebastian Elcano en el Gran Kuursal de San Sebastian. En su regreso a Barcelona en la década de los veinte del siglo pasado, los ballets russes de Diaghilev habían dejado de ser una novedad en España.

6 Programa de mano de la presentación de la temporada de 1924 de los bailes rusos de Diaghilev en el Teatro del Liceo. Bibliothèque Nationale de France (BNF), département Bibliothèque-musée de I'Opéra, AID-931 (5, 158-167) [https://gallica.bnf.fr/ark:/12148/ btv 1 b84150583].

7 En Diario de Barcelona, 8 de marzo de 1924, p. 2411.

8 Ver La Vanguardia, 18 de marzo de 1924, p. 12. Carol Hess ofrece de forma más detallada la acogida de "El sombrero de tres picos" por el público español tanto en Madrid como en Barcelona. Ver, HESS, Carol, (2002), pp. 131-146. 
llantísimo de las grandes solemnidades artísticas y mundanas" que presentaría el "Teatro de la Opera" barcelonés con las novedades "El sombrero de tres picos"10 y "L'apres midi d'un faune". Completaron el programa las ya conocidas por el público del Liceo "Les Sylphides" y "Carnaval"."

El crítico de La Vanguardia Walter, que ya cubrió las representaciones de los bailes rusos en la anterior gira del 18, escribió una amplía reseña de la sesión inaugural donde celebraba el éxito alcanzado entre el público las danzas de los bailarines rusos. Tras comentar sus impresiones sobre "Les Sylphides", describió ampliamente "Carnaval" y "El sombrero de tres picos". De esta última obra criticó el vestuario y el decorado cubista de Picasso, por "feo" uno y "violento y abigarrado" el otro destacando la música de Falla porque reunía "lo más hondo de la música popular" con un final de obra acabado en Jota "rico en ritmos, algunos brutalmente gitanos". La representación, interrumpida varias veces por los aplausos del público, fue "ovacionada al final", marcando un fuerte contraste con el ballet que le siguió y cerró la sesión, "La siesta del fauno". ${ }^{12}$

9 Diario de Barcelona, 19 de abril de 1924, p. 7.

10 Lydia Sokolova, la bailarina que hizo el papel de la Molinera junto con Leon Woizovsky qque interpretó al Molinero) en "El sombrero de tres picos", explicaba en un libro sobre su vida la propia experiencia previa al estreno del ballet en Barcelona y de cómo el público estalló en aplausos al finalizar su actuación. Teniendo que salir varias veces a saludar al escenario: "Barcelona had never seen our Spanish ballet before, and we were very nervous. Eve Zoia Roszovska, who had sign to the accompaniment of our clapping hands before the curtain went up, was apprehensive of making a fool of herself in front of the critical public of the largest city in Spain. But no sooner was Picasso's décor revealed in all its warmth of lighting, with Leon alone on the stage making his first Spanish movements, than the audience settle down to watch us intently, and at the end of the first par they showed their enthusiasm by a tremendous burst of applause. By the end of the ballet they were worked up into a frenzy, and we took so many curtain calls that some of the dancers were dressed and on their way out of the theatre before Leon and I could leave the stage. We were very happy". SOKOLOVA, Lydia (1960), p. 220. Respecto a su papel de la Molinera en el ballet "El Sombrero de Tres Picos", en su biografía también habla de cómo se sentía más cómoda bailando este papel con Woizikovsky que con Leonidas Massine, el creador de la coreografía, porque aunque era una danza a dúo en muchos momentos de la obra, Massine parecía siempre estar bailando solos: "I preferred doing this baller with Woizikovsky, because Massine even he was dancing as my partner, always seemed to be dancing a solo", SOKOLOVA, Lydia (1960) , p. 176.

11 "Les inaugurals i les estrenes d'ahir. Liceu", La Publicitat, 20 de abril de 1924, p. 6. El orden de actuación fue: "Les Sylphides", "Le Tricorne", "L'après-midi d'un faune" y "Carnaval". Ver La Vanguardia, 19 de abril de 1924, p. 12. 
Joan Llongueras en La Veu de Catalunya -que ya siguió a la compañía rusa durante las giras del 1917 y 1918 en Barcelona- dedicó una extensa crónica a cuatro columnas, empezando con el recorrido histórico de la compañía de Diaghilev en el mundo de la danza y acabando, con una reflexión sobre la perdida de esa etiqueta de novedad artística permanente que siempre había acompañado a su espectáculo. Respecto a las cuatro obras de la noche centró su atención en "El Tricorni", cuyo decorado y vestuario, a diferencia de Walter, lo calificó de "elegantemente estilizado" y una "veritable meravella de intenció i color" debido a la ausencia de detalles y accesorios en el vestuario- lo que por otra parte facilitaba la movilidad de los bailarines. La crónica también recogía sus impresiones en lo referido a la música de Falla, la coreografía y la propia reacción del público tras finalizar la representación. Desconcertado a partes iguales tanto por la escenografía como por la no comprensión de la obra:

"La música de Manuel de Falla, que no té la malicía ni del decorat ni de la coreografía, és justa de carácter i poderosament evocadora i significativa.
Es teixida amb danses i temés populars éspanoyls, sense, però deixar d'acusar-se en ella el segell personal del fort temperament músical que la ha creada. Segueix i dóna el moviment just a totos el incidents de la faula i caracteritza admirablemente els personatges. La partitura és molt treballada $i$ escrita amb traça i amb perfecte coneixement desl moderns recursos harmònics. En l'orquestació potser s'hi nota una certa duresa i sequetat, segurament volguda, ja que a nosaltres no ens hi destroba gens, ans bé, acaba s'apoiar el seu caràcter. Remarquém que la dansa de la molinera, el fragment dels raïms, un dels més inspirat i característics de l'obra, la dansa del moliner i el brillant apoteòsic final. En la coreografía de Massine hi ha un humor i una ironía adorables $i$ és poderosament expressiva i plena de caràcter tota ella. Potser la constant repetició de moviments d'influencia marcadament epiléptica la perjudica. Notàrem, sobretot en la segona part, algunes petites variants en l'acció, que no correspon en del tot amb la intenció de la música i que ens semblaren defectes $d$ 'interpretació....

12 Walter, "Liceo. Bailes rusos", La Vanguardia, 20 de abril de 1924, p. 15. Ver más reseñas en FIVE, "Els Balls Russos de Diaghilew al Liceu", La Veu de Catalunya, 20 de abril de 1924, p. 4. 
El públic del Liceu, aplaudí "El Tricorni" i l'admirable interpretació dels dansaires russos, però l'obra no fou plenament gustada i compresa, sinó d'una no molt nombrosa selecció. La major part restà desoncertada per l'audacia del decorat i per la crua i subtil estilització de la coreografia i de la música, sense la més petita compensació al mal gust habitual". ${ }^{13}$

Siguiendo con los elogios al ballet español El Correo Catalán ${ }^{14}$ y otras cabeceras como el Diario de Barcelona o El Diluvio celebraron la acogida que tuvo entre los espectadores del Liceo en función de los aplausos ofrecidos a su conclusión. Así mientras A. M., desde las páginas del Diario de Barcelona, calificaba la representación como de españolada, achacando su impronta española a la música de Manuel de Falla, de la que además, puso en valor la modernidad que traslu- cía. ${ }^{15}$ Alard, el crítico de espectáculos teatrales del diario El Diluvio, también mostró su admiración por lo moderno de las notas musicales del maestro gaditano en el ballet remarcando, sin embargo, que no perdiese la esencia de la obra original:

"Con un lleno inaguróse anoche la temporada de primavera del Liceo: butacas y palcos atestados de mujeres bonitas y en los pisos altos también la concurrencia numerosa. La compañía coreográfica que dirige Serge Diaghilew presentóse con interesantísimo programa, en el que figuraba la primera representación del bailable de Martínez Sierra, adaptación del cuento de Alarcón, "El Sombrero de tres picos", música de Manuel de Falla, que fué un éxito completo. Verdaderamente, el maestro Falla ha escrito una partitura hemosísima, en la que

13 J. LL., "Els Balls Russos de Diaghilew al Liceu", La Veu de Catalunya, 20 de abril de 1924, p. 4.

14 M., "Liceo. Inauguración", El Correo Catalán, 20 de abril de 1924, p. 5.

15 "Trátase de una spagnolade, en la que el talento músico de Falla se manifiesta de manera brillante, con todas las características de las corrientes modernas, habiendo dotado a su partitura de una música grácil e instrumentada de mano maestra. Si bien, como hemos dicho, hay en "El sombrero de tres picos. todas la características modernas, no por eso deja de serpentear por en medio de las modernidades armónicas una melodía fresca y espontánea, que lleva bien marcado el sello de la música española". A.M., "Bailes Rusos", Diario de Barcelona, 20 de abril de 1924, p. 39. En sus notas de sociedad, en el diario se afirmaba que el "todo Barcelona elegante y aristocrático se había dado cita en el Liceo" en "Notas de Sociedad", Diario de Barcelona, 22 de abril de 1924, p. 5. 
se destacan gran variedad de ritmos y riqueza de colorido orquestal. Se manifiesta un músico de profundos conocimientos, y especialmente artista de culto y de refinada sensibilidad. La musicalización de "El sombrero de tres picos" es sorprendente por todos conceptos, y más en los tiempos presentes, que parece haberse olvidado todo sentido de forma y estructura. Con todo y rendir tributo a las formas modernas, no olvida el carácter y el sentido interno del libro. Hay momentos afortunadísimos en la orquestación, así como el detalle, que no puede ser más conciso". ${ }^{16}$

En cambio apenas una nota informativa contenía el diario La Publicitat sobre la noche del estreno de la compañía de Diaghilev en la sección "Darrera hora". Destacaba en sus páginas la obra "El tricorni" y el éxito "complet" que tuvo su representación, emplazando para unos días más tarde, un análisis más profundo del acontecimiento artístico que constituían los bailes rusos. ${ }^{17}$ Tras la función inaugural se sucedieron dos días seguidos de representaciones, el domingo 20 de abril en horario de matinée con las obras "Carnaval", "Cleopatra" y "Petrouchka"18 y el lunes día 21 en horario nocturno con los bailes "Les Sylphides", "L'aprés midi d'un faune", las danzas del "Príncipe lgor" $y$ "Le Tricorne". ${ }^{19}$

De estas sesiones " $X$ " escribió una crónica en La Publicitat que recogía lo más señalado de estos dos días de ballets en el Liceo donde destacaba sobre las demás obras "Petrouchka", calificada por el crítico como de "obra maestra" por la "profunda impresión que dejaba en los sentidos. No solo por el argumento de su libreto, sino también por la partitura de Stravinsky -ya conocida por los espectadores del Liceo. Era una "maravilla" en palabras del crítico que sumo sus elogios al resto de obras representadas durante estas dos jornadas con excepción de "L'après midi d'un faune" y su recepción tan ponderada por parte del público:

"L'après midi d'un faune" fou
rebut amb general aprovació
i elogis. Per la nostra part, in-

16 Alard, "Liceo. Bailes rusos", El Diluvio, 20 de abril de 1924, p. 46.

17 "En parlarem amb l'atenció que mereix", "Les inaugurals i les estrenes d'ahir. Liceu", La Publicitat, 20 de abril de 1924, p. 4.

18 A.M., "Gran Teatro del Liceo. Bailes rusos", Diario de Barcelona, 22 de abril de 1924, p. 14.

19 La Publicitat, 20 de abril de 1927, p. 7. 
sistim en mostar la nostra humil disconformitat. La sensació de calma i ensomni que sembla es vol produir, sospitem que es podría obtenir per altres mitjans que els emprats, els quals donen a la dança un caràcter "estàtic"-no "estètic" com ahir ens fèu dir el nostre benvolgut linotipista- que no podem comprendre". ${ }^{20}$

En una crónica teatral publicada el día 22 de abril, Joan Llongueras desde La Veu de Catalunya, analizó las obras representadas hasta esta fecha empezando por las tres novedades que había traído la compañía de Diaghilev a Barcelona por primera vez: "El Tricorni", "Petrouchka" y "La tarda d'un faune". Este último ballet, al igual que al crítico de La Publicidad, no convenció a Llongueras aunque en su caso por el decorado que era: "horriblemente, desentonat i míser". Mas mesurada fue su crítica a "Cleopatra" y a "Las danzas del príncipe lgor". Respecto a "Carnaval" y "Les Silfides"21 fueron las interpretaciones que menor interés tuvieron para el público a juicio del crítico. Concluía su crónica con una valoración general de la troupe rusa y la acogida del espectáculo por parte de los espectadores presentes durante estas tres noches de danza en el Liceo:

"L'actual companyia de Balls russos de Diaghilew, és en conjunt, força notable, i hi ha en ella algunes figures de relleu, no totes certament desconegudes per nosaltres. Citem en primer lloc les senyores Nijinska, Tchernicheva, Nemtchinova, Sokolva, Nikitina, De Valois, Schollar, Doubrovsky, etc, i els senyor Wilzak, Woizikovsky, Zverw, Slawinsky, Jarvinsky, Doline i Kremmec. Els ballets són posats sota la direcció personal de Serge Diaghilew, i del "regisseur" general, Serge Grigorieff. Dirigeix l'orquesta el mestre Eduard Flament, qui demostra conixer bé el repertori, però que segurament s'ha vist

20 X., "Balls russos, segona i tercera representacións", La Publicitat, 23 de abril de 1924, p. 4.

21 "Carnaval" i "Les Sílfides" en plauen cada vegada menys. El primer és una frívola i banal fantasía carnaalesca que no té res que veure amb la música tan espirítual de Schumann. El esgon, un seguit de motius de dansa purament decoratius, damunt uns valsos, unes mazurques i uns preludis de Chopin, no pas triats d'entre els millor que sols pot plaure i enternir les dames i damiselles romàntiques i sentimentals. No ens sembla tampo un encert el portar l'orquesta una música tan fondament pianística como aquesta de Schumann i Chopin". Joan Llongueras, "Companyia de Balls Russos de Serge Diaghilew", La Veu de Catalunya, 22 de abril de 1924, ed. matí, p. 4. 
obligar a posar les obres amb excess va rapidesa i s'això se'n ressenten fins ara totes les interpretacions orquestals. El públic del Liceu ha rebut molt bè i ha prodigat novament els seus entusiastes aplaudiments a aquesta famosa manifestació d'art que amb tant encert l' Empresa del Gran Teatre ha fet reapareixer ente nosaltres, constituint, ara com ara, la més forta i vibrant actualitat de la vida artística barcelonina". ${ }^{22}$

La siguiente función tuvo lugar el 22 de mayo con un cartel compuesto por "El Sombrero de tres picos", "Petrouchka" y "Cleopatra". Sobre esta sesión escribió J. B. de P. en El Correo Catalán, que al igual que los otros críticos de espectáculos, continuaba a vueltas con la música de Falla y la creación del ballet de inspiración española por Diaghilev por considerarla una "producción musical de primer orden". Para el crítico de El Correo Catalán, no era otra cosa sino la música lo que hacía brillar la representación por encima de la impronta cubista o la propia escenografía:

"Volviendo a la producción de Falla se impone desde luego reputarla no como una curiosidad de arte nuestro aplicada y vivificada en el ambiente de otro arte completo de genialidades rítmicas y arbitrariedades de diseño y color lque caracterizan el cubismo en que se presenta la obra), sino una producción musical de primer orden. Engendrada por el númen popular, saturada de "vis" emotiva dentro de lo que permite un género en que todo es incidental, tiene el arranque viril que distingue a las grandes personalidades: y a la belleza de los temas rebosantes de espontaneidad junta un técnicismo magistral pero claro y transparente para que las letras del autor no queden embrolladas en la percepción del oyente. A no haber sido por la música que es el nervio de esta exhibición de arte danzante no habría resultado éste en que el cubismo extrema las líneas caticaturescas que viéronse en el cuento de Alarcón "El corregidor y la molinera". Realmente en estos cuadros de bailes rusos el problema de producción ha sido doble o predominantemente de plástica visualidad. Mas en El Tricornio es ante todo musical.

La plétora de ritmos que la troupe va destriando en escena de-

22 Joan Llongueras, "Companyia de Balls Russos de Serge Diaghilew", La Veu de Catalunya, 22 de abril de 1924, ed. matí, p. 4. 
terminando la incesante variedad de siluetas en las figuraciones coreográficas palidecieron ante la valentía y plenitud de la partitura de Falla, para quién fueron en gran parte los aplausos demostraciones de agrado que se produjeron en la sala, sobre todo en la Jota final" ${ }^{23}$

El día 23 de abril la compañía de Diaghilev presentó como novedad de temporada la obra "Thamar, el estreno de la trilogía "Contes Russes", "Carnaval" y las danzas de "El príncipe lgor". Sobre esta sesión El Diario de Barcelona ${ }^{24}$ y El Diluvio destacaron las actuaciones de los bailarines y la respuesta de un público que estuvo "desorientado" ante la representación de "Contes Russes":

"Anoche dióse por vez primera el "ballet" mímico de Liadow "Cuentos rusos", formado por una serie de episodios, algunos de ellos muy interesantes como cuadro plástico y nota de color. Claro que el público, un poco desorientado por no conocer el asunto ni el argumento que se estaba desarrollando mostró más de una vez sus reservas, más, sin embargo, el nuevo cuadro representado no puede negarse que tiene momentos muy apreciables, y sobre todo los artistas rusos estuvieron excelentes, distinguiéndose las señoras Nifinks, Tchernicheva, Korolovitch y los señores Weizikowsky, Sinvisky y Wilzak. La música del maestro Liadow es notable por su brillantez orquestal, aunque en algunos momentos languidece" ${ }^{25}$

Además J. Llongueras en La Veu de Catalunya, que también reflejo la pasividad de los espectadores durante la representación de "Contes Russes" -no muy aplaudida-, abría su crónica de la noche preguntándose sobre la falta de novedades en la programación de la compañía de Diaghilev. Reivindicaba así el crítico musical el ambiente moderno y avanzado de la vida artística barcelonesa comparable, en su vertiente musical, al de cualquier otra sociedad destacada del mundo artístico: "Sempre es troba en aquest
prodigiós espectacle quelcom
de sorprenente i d'inesperat.
Val a dir que ès això precisa-
ment allò que hi anem a cercar
i allò que voldriem ens haguès
sigut donat amb mès prodigali-
tat en aquesta actual "tournée"

23 J. B. de P., "Liceo. Bailes rusos", El Correo Catalán, 23 de abril de 1924, p. 3.

24 A.M, "Gran Teatro del Liceo. Bailes Rusos", Diario de Barcelona, 24 de abril de 1924, p. 39. 25 "Liceo. Bailes Rusos", El Diluvio, 24 de abril de 1924, p. 39. 
entre nosaltres. Obres del gènere "Thamar", que fou represa ahir a la nit, amb música (certament ben fluixa) de Balkirew, coreografía de Fokine i decorat i vestuari de Bakst, ha no ens poden interessar perquè res de nou ens aporten i l'emoció que ens podrien podruir és ja gastada i esmosada fa temps. La interpretació que donen a aquest ballet o drama coreogràfic els artistes russos és, com totes, ben notable i per això ens dol encara molt més que, tenint en compte la curta estada que fan en nostra ciutat, no esmercin les seves habílitats $i$ el seu talent $i$ el seu art en aquelles coses fortes i personal que consitueixen el "clou" del seu vast repertori. Ens referim a tota aquella sèrie de Ballets amb música de Ravel, de Straus, d'Erik Satie, de Strawinsky i d'altres autors mo- dernísims que han deixat la seva aportació magnifica a aquesta experiència artística tan plena de suggestions i revellacions; que és el "Ballet Rus". Diaghilew cal que s'adoni que hi ha a Barcelona una intensa vida artística que vibra a l'uníson amb l'ambient més avençat del món. L'exit recent de Strawinsky és un fet certament revelador." 26

El día 24 la sesión en horario nocturno comenzó con los ballets en un acto "Sylphides", "Thamar"27 $y$ "Contes russes" y con el estreno de "Cimarosiana", ${ }^{28}$ muy bien recibido por el público. ${ }^{29}$ El sábado 26 el programa lo componían "Petrouchka", "Pulcinella", "L'après-midi d'un faune" y las danzas de "El príncipe lgor". ${ }^{30}$ "Pulcinella", el estreno de la noche, creó críticas dispares en los diferentes medios que venían siguiendo la evoluciónes de

26 Joan Llongueras, "Balls russos de Diahilew", La Veu de Catalunya, 24 de abril de 1924, p. 7.

27 Walter valoraba la obra integra en su conjunto porque no creía que la música ni la coreografía tuvieran un "gran interés" si bien las posibilidades escénicas que la danza ofrecía al público eran de agradecer. Aunque muchos los espectadores no le prestaron la atención que la representación "merecía". Walter, "Liceo. Bailes Rusos", La Vanguardia, 25 de abril de 1924, p. 17.

28 X. "Liceu. Balls russos. Cimarosiana", La Publicitat, 27 de abril de 1924, p. 6.

29 A.M, "Gran Teatro del Liceo. Bailes Rusos", Diario de Barcelona, 25 de abril de 1924, p. 31 . En páginas anteriores a la crónica teatral también se aseguraba que no se prolongaría el contrato de la compañía de los bailes rusos en Barcelona al tener ya la compañía de Diaghilev contratos cerrados en Holanda, París y Londres. "Teatros y Cines", Diario de Barcelona, 25 de abril de 1924, p. 14.

30 La Publicitat, 26 de abril de 1924, p. 8. 
la compañía rusa con una resonancia en la prensa, por la colaboración de Picasso, casi comparable a la generada por "El sombrero de tres picos". "X", en La Publicitat destacó por encima del decorado de Picasso y la coreografía de Massine, el vestuario y la colaboración vocal de Concha Callao y Dimi i Giralt en la representación junto con el gran trabajo de los bailarines Woizikovsky y Sokolova sobre el escenario. ${ }^{31}$

Las crónicas de El Diluvio el día 27 de abril ${ }^{32}$ y del Diario de Barcelona el 29 de abril de 1924 respectivamente, también recogían el estreno de "Pulcinella" con críticas al decorado. En este último periódico se destacó la interpretación de Woizikovsky y la gran solvencia de la orquesta bajo la dirección del maestro Flament, aunque para el cronista, Picasso podría haber dado "más de sí" en la creación del decorado bajo las "teorías cubistas":

"Si bien en cuanto al decorado del "ballet russo" estamos conformes y juzgamos una necesidad salirse del realismo, e incluso ampararse en las teorías cubistas, creemos, no obstante, que Picasso hubiera podido dar más de si en "Pulcinella", que, en verdad se presta en gran manera y da lugar a mayores agudezas de construcción y color... Strawinsky puso en la partitura de "Pulcinella" un sin número de dificultades, obligando a cada instrumento de por sí a dar todo el rendimiento posible y obligando al conjunto orquestal a actuar con dificultades de solista. Estos escollos supieron salvarlos los profesores de la orquesta y no menos el maestro Flament, que con acierto la dirigió".$^{33}$

Por su parte B. de P. en El Correo Catalán mostró interés y valoró la adaptación que Igor Stravinsky había hecho de la partitura de Pergolesi -ya conocida por parte de los asiduos al Liceo- y su orquestación para ballet, aunque también reflexionaba sobre el trabajo realizado por el compositor ruso en un proceso de adaptación "caricante" porque había derivado en una mayor dificultad técnica en su ejecución musical:

"Ha sido el último estreno de los bailes rusos. Interesaba mucho esta obra "sui generis" puesto que en los conciertos de Strawinsky se dió una "suite"

31 "A.", "Balls russos. Pulcinella", La Publicitat, 29 de abril de 1924, p. 4.

32 "A.", "Liceo. Bailes rusos", El Diluvio, 27 de abril de 1924, p. 27.

33 "Bailes rusos. Estreno de Pulcinella", Diario de Barcelona, 29 de abril de 1924, pp. 9-10. 
compuesta de fragmentos de aquella; y según dijimos en la reseña obligada y con la satisfacción de consignas unéxito, "Pulcinella" es una partitura tejida por el genial compositor ruso con música del clásico napolitano J. Battista Pergolesi. Dada ahora la obra por completo y con el aliciente de la representación danzante se echa de ver pronto que el capricho de Strawinsky va a derivar en caricatura; y así como el caricaturista al exagerar los rasgos de la fisonomía y al fantasear grotescamente con la silueta del caricaturizado, le reconoce la importancia, Strawinsky rinde pleitesía al músico italiano, "caricando" enormemente los rasgos característicos de su época y sus formas musicales y transcribiendo pulcramente melodías pergolesianas; pero escapa, también al terreno peligroso de la arbietrariedad armónica y rítmica del cual vuelve a salirse muy airoso.... Esto último hace también difícil una ejecución cabal de la partitura de "Pulcinella", verdaderamente erizada de asperezas en ciertos pasajes de los instrumentistas". ${ }^{34}$

Por último Walter en La Vanguardia encontró en "Pulcinella" una obra que "divirtió" al público con su escenografía y música a la que calificó de caricaturesca. ${ }^{35}$ Pero esta diversión para el espectador de la que hablaba Walter, provocada por interpretación de los bailarines y la propia escenografía del ballet, no evitó la confusión del público ante lo visto en el escenario del Liceo, y como en noches anteriores, la reacción de los espectadores fue de desconcierto, hecho que también confundió a los propios redactores de La Publicitat. ${ }^{36}$ La siguiente función fue fijada el 29 de abril de 1924 a las nueve y media con un nuevo estreno en cartelera "Dafnis y Cloe", aunque abrió la noche "Cleopatra". Completaron el cartel "Carnaval" y "Cimarosiana". ${ }^{37}$ En el estreno de "Dafnis y Cloe" con música del compositor Maurice Ravel, coreografía de Michel Fokine, escenografía de Leon Bakst y vestuario de Juan Gris, fueron las interpretaciones de los bailarines principales de la compañía como

34 B. de P., "Liceo. Pulcinella", El Correo Catalán, 30 de abril de 1924, p. 3.

35 Walter, "Bailes Rusos. Pulcinella", La Vanguardia, 27 de abril de 1924, p. 21.

36 "No es dirá aquesta vegada que les audacies del músic puguin inspirar cap desconfiança, ni la interpretació coreográfica no presenta tampoc cap complicació ni el vestuari és d'un cubisme alarmant...Però, malgrat tot això, els aplaudiments de l'auditori tingueren un to d'indecisió incomprensible". "Darrera hora. De Barcelona. Liceu", La Publicitat, 27 de abril de 1924, p. 8.

37 La Publicitat, 29 de abril de 1924, p. 7. 
Lydia Sokolova ("Cloe"), Antonio Doline ("Dafnis"), Nicolas Zverev ("Darkon") o Maikerska ("Lyccion") lo que más destacó la mayoría crítica barcelonesa. En cambio para Walter en La Vanguardia, fue la dirección del maestro Flamenent al frente de la orquesta del Liceo lo más destacable de la sesión: "realizo un excelente trabajo, verdadero tour de force dadas las dificultades de la partitura" ${ }^{38}$ No tuvo la misma opinión Joan Llongueras porque, a diferencia de Walter, calificó de "discreta" tanto la dirección musical de Flamenent como la interpretación del bailarín principal Antoine Doline. Sin embargo, como crítico con una gran formación musical firmó un extenso análisis de todos los elementos musicales de esta obra de Ravel a la que calificó de "magnífica sinfonía coreográfica". Pensaba Llongueras que era una de las producciones "más fuertes" de todo el repertorio de ballets de Diaghilev:

"Deixant a part el ballet i l'acció escènica, "Dafnis i Cloe" de Ravel pot considerar-se musicalment com una poderosa i ben construïda simfonia escrita per un dels més brillants i suggestius virtuosos de l'orquestra moderna. Es divideix aquesta obra en tres temps i dos intermedis. Allò que caracteritza els temps és l'acció, és la faula poemàtica, que Ravel segueix i comenta pas a pas amb fina i lúcida musicalitat, sense, però caure mai en descriptivismes fàcils i vanals" ${ }^{39}$

" $\mathrm{X}$ ", desde las páginas de La Publicitat, al igual que Llongueras dedicó una extensa crónica "Dafnis i Cloe" a la que consideraba como "un dels blocs més ferms de la música contemporània i com una de les manifestacion més significatives i reeixides de l'art francès" debido a la música de Ravel. Aunque en su opinión la partitura creada por Ravel no era escenificable, como otras producciones del repertorio de Diaghilev, pese a que consideraba las danzas de esta obra como una "veritable delicia",

"Renunciem per avui a les disgressions que hauríen de fer per fonamentar la nostra manera d'apreciar aquesta producció i expressar del tot el nostre pensament, i comencem per on hauríem acabat. Diguem-ho clar: la coreografía, o, més precisament, la plàstica ens hi fa nosa. No que la interpretació de Fokine no sigui admirable en tots el sentits, interessantísima

38 Walter, "Bailes rusos. Dafnis y Cloe", La Vanguardia, 30 de abril de 1924, p. 18.

39 J. LL, "Balls russos de Diaghilew. Dafnis i Cloe", La Veu de Catalunya, 2 de mayo de 1924, p. 4. 
com a realització r'timica i plena de subtileses que s'adiven amb el caràcter de la musica; sinó que per a nosaltres aquesta música no és del tot "interpretable" plàsticament, i el tema que glossa no ens expliquem, que almenys reduit en la forma que ens és essencial, com ha pogut temptar a Ravel per portar-lo a l'escena...Al començament de les sessions de Balls Russos i a propósit d'algunes representacions que no ens van plaure, insinuàrem que ens sembla un error creure que a tota la musica i a totes les obres musicals escau la interpretació plàstica o la coreografia. Ara podem insistir en al nostra apreciació, afegint ecara que fins moltes obres escrites amb aquest intent tot $i$ essent ben reeixides sota determinat aspecte, podem no reunir condicions pe a l'escena, equivocant-se l'autor i fracassante en l'assaig si no està especialment preparat per al gènero 0 no té encert a triar el tema. Prescindint ara d'aquests punts de vista, hem de dir que la musica de "Dafnis i Cloé" és una meravella de capa a cap". ${ }^{40}$
Las sesiones de despedidas de bailes rusos del Gran Teatro del Liceo para esta temporada de 1924 se programaron a las 21:30 horas el día 30 de abril, miércoles, con las obras "Carnaval", "Dafnis y Cloe", "Pulcinella" y las danzas de "El príncipe lgor" 41 y el jueves 1 de mayo con un cartel final de actuaciones que se configuró con "Sylphides", "Cleopatra", las danzas de "El príncipe lgor", y "Le Tricorne". ${ }^{42}$

\section{Año 1925. Nuevos tiempos: la RADIO Y EL FC BARCELONA}

Un año más tarde, en mayo de 1925, volvían los bailes rusos al Gran Teatro del Liceo con un imprevisto que afectó a la planificación de la temporada a su llegada a Barcelona. Anunciados los nuevos espectáculos de la compañía de Diaghilev desde el mes de abril, la empresa que gestionaba el teatro barcelonés exigió el cambio en la dirección de la orquesta del maestro François Defosse antes del inicio de las sesiones. ${ }^{43}$ Así una vez ya configurado el plantel definitivo de la compañía para su gira en Barcelona la función inaugural se programó el sábado 2 de mayo a

40 "X", "Liceu. Balls Russos. "Dafnis i Cloè", La Publicitat, 2 de mayo de 1924, p. 4.

41 La Publicitat, 30 de abril de 1924, p. 8.

42 La Vanguardia, 1 de mayo de 1924, p. 13.

43 Al parecer la empresa Mestres que gestionaba el Liceo se negó a aceptar a Defosse como director de orquesta lo que motivo la contratación de Eugenio Goosens en BUCKLE, Richad (1984), p. 453. 
las 21:45 con las obras "Les sylphides", el estreno en España de "Les tentations de la Bergère", "Cimarosiana" y "Scheherezade". ${ }^{44}$ Como novedad extraordinaria, respecto a temporadas pasadas, las representaciones de los ballets russes en el Liceo fueron trasmitidas por primera vez en directo en España desde la frecuencia de Radio Barcelona. ${ }^{45}$

\section{La Veu de Catalunya ${ }^{46}$ y el Diario} de Barcelona recogieron en sus respectivas secciones de espectáculos el debut de la compañía rusa, destacando la colaboración en decorados y vestuario del pintor catalán Juan $\mathrm{Gris}^{47}$ junto con las interpretaciones de los bailarines:

"Como estreno constaba "Les tentationes de la Bergere", música de Monteclair, reconsituída e instrumentada por H. Casadesús y coreografía de Nijinksy. Su música que lleva toda la claridad y frescura clásicas, unida a la riqueza de color de los trajes y la magnífica interpretación que obtiene, hacen de este ballet una preciosa escena. Fué (sic) acogido cono mucho agrado. Muy aplaudidos fueros todos los interpretes y especialmente las partes principales señoras Tchernicheva, Nikitina, Coxom, Sanina, Nemtchinova, Doubrowska, Nima de Valois, Sokolova y señores Woizikowsky. Ydzkowsky y Doline todos los cuales realizaron la exquisita labor que corresponde al renombre alcanzado por esta compañía. Constituyó, pues, la función de anoche un nuevo éxito que pueden apuntarse los tan notables bailarines rusos" ${ }^{4}{ }^{4}$

44 Programa de la función inaugural del día 2 de mayo de 1925, BNF, département Bibliothèque-musée de l'Opéra, AID-931 15, 320-342) [https://gallica.bnf.fr/ark:/12148/btv1 b8415069w].

45 "Retransmisión de los bailes rusos cuya presentación tendrá lugar hoy en el Teatro del Liceo". La programación del día se puede ver en la sección de Radiodifusión del Diario de Barcelona, 2 de mayo de 1925, p. 34. Radio Barcelona (EAJ-1), se inauguró el 14 de noviembre de 1924 con un discurso transmitido en directo del Alcalde de Barcelona teniendo como sede el Gran Hotel Colón. La Vanguardia, 14 de noviembre de 1924, p. 4. El Reglamento de Radiodifusión a nivel nacional entró en vigor 5 meses antes el 14 de junio de 1924. Ver más en GARITAONAINDIA, Carmelo (1988), pp. 19-21.

46 "Les temptations de la pastora o el triomf de I'amor", La Veu de Catalunya, 3 de mayo de 1925, p. 8.

47 Juan Gris tuvo su primer contacto con Diaghilev en enero de 1917 en París, con ocasión de la venta de unos cuadros. Gris que residía en París en esos años, compartía con el también pintor Diego Rivera marchante de arte y relaciones comunes con otros artistas de las vanguardias parisinas que frecuentaban los cafés de Montparnasse. Ver, GRIS, Juan (2008), pp. 134-114. 
La siguiente sesión programada en horario matinée el día 3 de mayo traía un nuevo estreno para el público del Liceo "Le train blue". Completaban el cartel "Cimarosiana", "Scheherezade" y las danzas de "El príncipe lgor". ${ }^{49}$ Walter, desde las páginas de La Vanguardia centraba su crónica en la novedad de la noche..$^{50}$ Por su parte, B. de P. en El Correo Catalán dejaba sus impresiones de las dos primeras jornadas de bailes rusos en Barcelona en una crónica protagonizada por los estrenos de la nueva temporada "Les tentations de la Bergère" y "Le train bleu". En ella criticó de forma amplía "Le train bleu", la obra ideada por Jean Cocteau, porque a su juicio no tenía mucha cabida en la idiosincrasia del teatro barcelonés a diferencia de otras obras de la compañía de Diaghilev:

"Otro estreno ha sido "Le train bleu", música de D. Milhaud. Se trata de la adaptación de una opereta, excesivamente ligera para el Liceo, aunque que se tenga en cuenta que se halla el espectador en el ambiente coreográfico. En el noble marco del primer teatro barcelonés desentona el asunto de la obri- ta, aunque el público la aceptó benevolamente y no dejó de aplaudirla. El arte serio vióse pronto desquitado en "El Príncipe lgor" y anteriormente en "Cimacorianas" y en "Shcherazade" pudro brillar en todo su prestigio, merced a la importancia de sus partituras y a la excelencia de los varios factores que determinan el espectáculo excepcional, es decir único de los "Bailes rusos". 51

Otra visión del estreno la aportó A.M en el Diario de Barcelona, quién aunque consideró la música de Milhaud algo "trivial" era, sin embargo, la adecuada conforme al argumento del ballet:

"Le train bleu' son una serie
de escenas de playa en las que
diferentes sports y juegos son
interpretados coreográficamen-
te, adquiriendo un animado y
bello conjunto. La música que
ha escrito Darius Milhaud, aun-
que de carácter algo trivial se
adapta con su animado ritmo
al ambiente del asuno. "Le train
bleu" gustó, y admiróse el arte
de los tan notables bailarines

48 A.M., "Debut de la compañía de bailes rusos", Diario de Barcelona, 3 de mayo de 1925, p. 39.

49 La Publicitat, 3 de mayo de 1925, p. 9.

50 Walter, "Bailes rusos. Le train bleu", La Vanguardia, 5 de mayo de 1925, p. 14. Ver reseña sobre esta sesión en CASTILLO, Pedro (2017), p. 258.

51 B. de P., "Bailes Rusos. Liceo", El Correo Catalán, 5 de mayo de 1925, p. 2. 
rusos que en esta obra como en todas están notabilísimos". ${ }^{52}$

\section{El 5 de mayo a las 21:30 horas} se representaron "Les tentations de la Bergère", "Carnaval", "Le train bleu" y "Cleopatra". ${ }^{3}$ El miércoles 6 de mayo el cartel lo formaron las obras "Scheherezade", "Contes russos", "Carnaval" y la danzas de "El príncipe lgor". ${ }^{54}$ El Diluvio, que no había publicado nada hasta la fecha sobre las actuaciones de los bailes rusos este año de 1925, reflejaba en su sección de espectáculos el éxito de público que estaban teniendo:

"Los bailes rusos es algo que seduce. Díganlo sino los entradones que se han registrado estos días en el Liceo, lo que demuestra el buen gusto de nuestro público, no ya 'solo en lo que podríamos llamar de nuestra aristocracia, sí que también en honor a la verdad del público popular, que, abigarrado en los pisos altos, ha hecho ostentación de su alto criterio artístico premiando con calurosos aplausos una actuación que sólo ha tenido de censura el hecho de dar tan pocas funciones". "La actuación de la compañía de bailes rusos en el Liceo. ${ }^{55}$

El día 7 jueves a las 21:30 se abrió la sesión nocturna con "Cimarosiana", seguida de la novedad "Le mariage d'Aurore" y cerraron la función "Le train bleu" y "Cleopatra" ${ }^{56}$ Respecto al estreno de la noche B. de P. en El Correo Catalán describía "Las bodas de Aurora" como una "producción que merecía el aplauso" pese a que no era nada "extraordinaria" y contaba con una música que servía de "pretexto" al género principal de esta obra: "la danza". En la representación sobresalió por encima de los demás bailarines Vera Nemtchinova. ${ }^{57}$ Distintas opiniones tuvieron los redactores de La Vanguardia ${ }^{58}$ y

52 A. M., "Gran Teatro del Liceo. Bailes Rusos", Diario de Barcelona, 5 de mayo de 1925, p. 24.

53 La Publicitat, 5 de mayo de 1925, p. 9.

54 Diario de Barcelona, 6 de mayo de 1925, p. 32.

55 El Diluvio. 7 de mayo de 1925, p. 3. Curiosamente misma nota de prensa se reproducía idéntica en el diario El Correo Catalán, bajo el título "El Liceo y los Bailes Rusos", el día 10 de mayo de 1925, p. 2. Ver también la crónica de Walter, "Las bodas de Aurora-Cuentos de hadas", La Vanguardia, 8 de mayo de 1925, p. 16.

56 La Vanguardia, 7 de mayo de 1925, p. 14.

57 "Balls russos. Le mariage d'Aurores", La Veu de Catalunya, 8 de mayo de 1925, p. 8.

58 Walter, "Las bodas de Aurora-Cuentos de hadas", La Vanguardia, 8 de mayo de 1925, p. 16. 
el Diario de Barcelona ${ }^{59}$ porque en sus respectiva crónicas, destacaron la coreografía y las buenas interpretaciones del cuerpo de baile de la compañía y en concreto, en este caso al igual que El Correo Catalán, de Vera Nemtchinova.

El sábado 9 de mayo el cartel se compuso de los ballets "Contes russes", "La boutique fantastique" (estreno), "Le mariage d'Aurore", y las danzas de "El príncipe lgor". 60 Las crónicas de la sesión aparecidas tanto en La Vanguardia como en La Veu de Catalunya subrayaron la orquestación que se hizo de la obra original de Rossini para "La boutique fantastique". Para el cronista de La Veu de Catalunya lo mejor de la obra era, sin dudas, la música para el ballet a la que cali- ficó de "potpourri". Algo habitual, por otro lado, en la compañía rusa porque creaba la producción musical a partir de la partitura de un autor, en esta ocasión Rossini, y la orquestaba para su representación en ballet otro músico distinto (Ettorio Respoghi). ${ }^{61}$ En cambio Walter en las páginas de La Vanguardia señaló la composición de Rossini como de "superior" en comparación a la "ampulosamente hueca" música de Tchaikovsky orquestada para "Le mariage d'Aurore". Con una bien ejecutada parte musical por el maestro Goosens a cargo de la orquesta del Liceo, fue la coreografía lo más interesante del estreno de la noche a pesar de su "pueril argumento". ${ }^{62}$ La interpretación "gustó" y fue "muy aplaudida" por el público. ${ }^{63}$

59 "Bailes rusos. Estreno Le mariage d'Aurore", Diario de Barcelona, 9 de mayo de 1925, p. 18.

60 La Publicitat, 9 de mayo de 1925, p. 7.

61 "Balls russos. La boutique fantastique", La Veu de Catalunya, 10 de mayo de 1925, p. 4. Respecto a la música de "La boutique fantastique", también El Correo Catalán, alababa la transformación de la partitura de Rossini realizada por Respighi, calificando su propuesta de "modernidad relativa": "La facilidad melódica de Rossini que nadie pueso en duda ha venido aun ha corroborarlo hace pocos días en alguna de sus obras reproducidas según su peculiar manera en el "Teatro dei Piccolí" que actuó en el Goya y por "La Boutique fantasque" a cuyos temas prestó mucho relieve el maestro Respighi, aplaudido autor de "Le fontane di Roma" al reinstrumentar una sencilla obra musical y aderezarla armónicamente dentro de unos límites que sólo implican propósitos de modernidad relativa. Así procedía y la agradable partitura prestase a la variadísimas suites bailable en la cual hay de todo como en botica, pero no decae nunca en interés artístico-coreográfico y suscita en todos o en casi todos sus número los aplausos espontáneos del público", B. de P. "Liceo", El Correo Catalán, 12 de mayo de 1921, p. 6.

62 Walter, "Bailes rusos. La boutique fantastique", La Vanguardia, 10 de mayo de 1925, p. 19.

63 "Estreno de La boutique fantastique", Diario de Barcelona, 13 de mayo de 1925, p. 17. 
El lunes 10 de mayo se representaron "Carnaval", "El lago de los cisnes" y "Scheherezade". El estreno de un ballet como el "Lago de los cisnes" con música de Tchaikovsky, coreografía de Marius Petipa y decoración de Korovine y Golovine no producido bajo la idiosincracia diaghileviana, no satisfizo a la crítica ni a los espectadores del Liceo, acostumbrados ya a la "modernidad escenográfica" de las producciones del empresario ruso. Sobre este hecho tanto las crónicas de La Veu de Catalunya ${ }^{64}$ y de La Vanguardia ${ }^{65}$ coincidían en considerar el ballet de Petipa como una obra con poco interés para el público (creía la crítica que fue creada para lucir las habilidades coreografías de los bailarines). En la misma línea, "A.", desde El Diluvio, incluso llegaba a cuestionar la propia autoría de Tchaikovsky en el ya ci- tado "El lago de los cisnes":

"Poca cosa tiene de notable la música de este "ballet", firmada por fragmentos de composiciones del maestro Tchaikowsky, que precisamente parece que se hayan escogido los trozos más triviales y banales que el compositor rusos escribiera. Por otra parte, el asunto es también un poco cursi, no teniendo de notable nada más que las acertadas escenas coreográficas, combinadas todas ellas con el acierto y el buen gusto característico de la compañía de Diaghilev...Lo demás, como hemos indicado, todo muy languido y hasta pesado, sobre todo el segundo acto. Hasta llegamos a suponer que toda la música no pertenece a Tchaikowsky". .6

64 "Balls russos. Le lac des cygnes", La Veu de Catalunya, 13 de mayo de 1925, p. 3.

65 Walter a pesar de calificar este ballet de vulgar le causó buena "impresión" la puesta en escena por la "bella realización plástica de los grupos de mujeres-cisnes, de un efecto encantador de una suavidad de líneas y de colores del más refinado gusto". A ojos del crítico de La Vanguardia, salvaron el estreno las grandes interpretaciones, a diferencia de la música, de Anton Doline y Stanislao Ydzikovsky, que junto a Vera Netmchinova, Alice Nikitina, Alexandra Danilova o Lidia Sokolova fueron los grandes ovacionados de la noche: "Era una idealidad estética que para llegar a su grado máximo sólo requería de una música más distinguida más evocadora. La belleza de las actitudes y de los conjuntos, logrados por las artistas todo es muy difícil de superar, al revés de lo que ocurre con la realización sonora de Tchaikowsky. ¡Cómo echamos de menos las ricas sonoridades y la exhuberante fantasía que caracterizan "El pájaro de fuego. Servían de marco al Lago el Carnaval y Scherezade. O sea un marco infinitamente superior al lienzo". "Bailes rusos. El lago de los cisnes", La Vanguardia, 13 de mayo de 1925, p. 15.

66 "A.", "Liceo. Bailes rusos. Le lac des cygnes", El Diluvio, 12 de mayo de 1925, p. 39. Otras cabeceras como El Correo Catalán pasaban por encima de análisis escenográficos y musica- 
La última de las funciones de abono programada de esta temporada de primavera del año 1925 tuvo lugar el martes 12 de mayo con las obras "Les Sylphides", "Petrouchka", "Le mariage d'Aurore" y las danzas de "El príncipe lgor". Sin reseñas en las crónicas periodísticas tras esta sesión, la compañía de bailes rusos prolongó su estancia en el liceo durante dos noches más de lo previsto en su planificación inicial. La primera de ellas gracias a los éxitos deportivos alcanzados por el Fútbol Club Barcelona.

La noche del 13 de mayo el teatro Liceo que lucía con la fachada decorada con "luces eléctricas" y con los colores del equipo "Fútbol Club Barcelona", fue el lugar escogido para homenajear al reciente campeón de los campeonatos de fútbol de España y de Cataluña. ${ }^{67}$ El acto consistió en un programa mixto de obras de ballet y piezas para música de orquesta. Los jugadores del Barcelona a su llegada al Liceo fueron recibidos a en el foyer del salón por el propio empresario del liceo
Joan Mestres y el antiguo líder de la Lliga Regionalista, y miembro de la Junta de Propietarios, Bertrand i Serra. Todos ellos, junto con el presidente del equipo Joan Gamper ocuparon dos palcos reservados en el segundo piso del anfiteatro engalanados con los colores azul y grana. Accedieron a ellos una vez comenzada la sesión cuando se interpretaba "El lago de los cisnes", que abrió la velada, siendo interrumpida por el gran aplauso con el que fueron recibidos los jugadores al ocupar sus localidades. ${ }^{68} \mathrm{~A}$ continuación de esta obra siguió la actuación de la Banda Municipal dirigida por Lamonte de Grignon que interpretó la pantomima de la obra "Las Golondrinas", las sardanas "A la plaça", "La Rosa del folló" y la "Obertura de Tannahauser". Cerró la noche el ballet "Le train bleu". ${ }^{69}$

Tras esta sesión homenaje al FC. Barcelona llegó la función de despedida de los bailes rusos del Gran Teatro del Liceo que tuvo lugar el jueves 14 de mayo con la programación de las obras "Schehereza-

\footnotetext{
les tan ajustados a la representación para justificar en líneas generales la calidad y ejecución de la compañía de bailes rusos. Destacando otros aspectos de la obra como la difícil interpretación que tuvo que realizar el violinista Munné de algunos fragmentos de la partitura pese a no estar ni la música ni la obra a la altura de otros ballets de la compañía. "B.", "Liceo. Bailes rusos", El Correo Catalán, 14 de mayo de 1925, p. 4.

67 La Publicitat, 12 de mayo de 1925, p. 10.

68 "Homenaje al F.C. Barcelona", El Diluvio, 14 de mayo de 1925, p. 39.

69 "Gran Teatro el Liceo. Función homenaje al F.C. Barcelona", Diario de Barcelona, 14 de mayo de 1925, p. 31.
} 
de", "Cuentos rusos", "Petrouchka" y las danzas de "El príncipe lgor". ${ }^{70}$ Aunque la mayoría de la prensa celebró la buena acogida por parte del público, la compañía de Diaghilev lamentó que la empresa de Mestres no hubiera podido llegar a un acuerdo con el empresario ruso para una última función extraordinaria. En ella se hubiese representado "La Leyenda de Joseph" con motivo de la visita de los reyes de España a Barcelona, en concreto en los días que van del 26 de mayo al 4 de junio. ${ }^{71}$

\section{Año 1927. La ÚlTIMA GIRA}

Después de actuar en la recién inaugurada temporada de primavera en Montecarlo y con previa parada en Marsella, los Bailes Rusos de Diaghilev reaparecían en Barcelona dos años más tarde un sábado 7 de mayo. ${ }^{72}$ El programa del estreno se configuró con "Les Sylphides", la novedad "Les matelots" y la "La boutique fantastique". ${ }^{73}$ A.M, en el Diario de Barcelona, sin entrar en una valoración más profunda en el caso de "Les Sylphides" o "La boutique fantastique", centró su crónica en el estreno de "Les matelots" porque era una creación de Boris Kochno que llevaba el puño de Pedro Pruna en la autoría del decorado. No obstante ni la música de George Auric ni la escenografía del pintor catalán, a las que calificó de gusto de "ultima hora", 74 tuvieron una valoración positiva por parte del crítico teatral. Tan solo la actuación de los bailarines hicieron que la representación no perdiera su interés:

70 La Publicitat, 13 de mayo de 1925, pp. 7-8.

71 "Declaraciones del Marqués de Viver", Diario de Barcelona, 16 de mayo de 1925, p. 28.

72 Diaghilev solo estuvo la primera semana de representaciones en el Liceo porque se tuvo que marchar a París a trabajar en una posible celebración del XX aniversario de los ballets russes. BUCKLE, Richard (1984), p. 457.

73 La Publicitat, 7 de mayo de 1927, p. 12.

74 También " $X$ ", desde las páginas de El Diluvio, hablaba de los bailes rusos como un espectáculo vanguardista, cuya obra "Les maletots", era fiel reflejo de ese espíritu: "Espectáculo para el regalo de los sentidos, de vagas sensaciones epidérmicas, pero salpicado de "esprit" y orientado casi siempre en un gusto muy " $D$ 'avant-garde", como ocurre en el ballet "Los marineros"...", X., "Bailes rusos de Diaghilew", El Diluvio, 8 de mayo de 1927, p. 36. 
A ésta, en el "Ballet" "Los marineros" le salva la vivacidad rítmica. Pero todo lo que pudiera decirse de la música y del decorado queda velado ante la labor admirable que realizan las señoras Danilova y Petrova y señores Woizikovsky, Slavinsky, Lifar y Cieplmsky. Hay verdadero espíritu en la mímica danzada de estos artistas. Por esto el "ballet" "Los marineros" no pierde en ningún momento el interés y por esto el público aplaudió mucho al terminar su representación". ${ }^{75}$

De la misma opinión era el cronista de El Correro Catalán B. de P., era el ritmo de la coreografía lo que hacía que la representación mantuviera su interés:

"Los ritmos originales y de gran vitalidad adecuados a un sentido de inquietud discolada y a veces de armonía muy disonante, sostienen el carácter de la obra, imbuída en una interpretación cubista de la pantomima y del bailes, forma muy gene- ralizada en estos espectáculos, que alguna vez derivan en licencia más aparente que real, ya que el asunto de ellos es de admirable amenidad". ${ }^{76}$

En cambio críticos como Joan Llongueras en La Veu de Catalunya ${ }^{77}$ y "G.", en La Publicitat encontraron en el trabajo de Pruna de "Les Matelots", además de la coreografía y la actuación de los bailarines. Por contra, la música les pareció que no aportaba nada a esta obra:

La partitura de "Les Matelots", condimentada amb ritmes oportunistes $\mathrm{i}$ algunas harmonies ja catalogades, no aporta res de nou que hom pugui prendre en consideració. La coreografía,amb força matissos també oportunistes, acrobàtica i molt en caràcter, entreté agradablement. L'execució dels dansaires, excelent.

El que millor ha reeixit en la composición d'aquesta obra és el pintor Pruna, que ha pintat un decorat molt notable, entonat $\mathrm{i}$ ple de suggestions. ${ }^{78}$

75 A.M., "Debut de la compañía de bailes rusos", Diario de Barcelona, 8 de mayo de 1927, p. 35.

76 B. de P. "Liceo. Bailes Rusos", El correo Catalán, 8 de mayo de 1927, p.6.

77 J.LL., "Els balls russos de Serge de Diaghilew", La Veu de Catalunya, 11 de mayo de 1927, p. 6.

78 "G", "Balls russos", La Publicitat, 10 de mayo de 1927, p. 6. 
$Y$ es que escenografía a parte, el tema de la música en su parte interpretativa ya venía siendo señalada por el propio Llongueras desde su primera crónica sobre este ballet. En general, consideraba poco trabajada la orquesta bajo la dirección del maestro Goosens. ${ }^{79}$

El día siguiente al estreno de la compañía en Barcelona, domingo 8 de mayo, se programó una sesión de tarde con las obras "Les Sylphides", "Les matelots" y por primera vez esta temporada "Carnaval" 80 El martes 10 de nuevo en sesión nocturna en la cartelería del Liceo se anunciaron los ballets "La boutique fantastique", como novedad "Les Biches" $y$ "Le mariage d'aurore" ${ }^{81} \mathrm{En}$ este caso el estreno de "Les Biches" acaparó la atención de las crónicas de la sesión.

"X." en La Publicitat criticó la partitura de Poulenc porque decepcionaba en su búsqueda de clichés sin éxito para dotar a la obra de un carácter cómico que no conseguía. Donde la pretendida modernidad musical creaba en el ballet una representación más propia de revista que de un teatro como el Liceo. Solo salvaba la obra por la coreografía y las actuaciones de los bailarines rusos. También pareció entender que el público no estaba ante algo excepcional por su pobre respuesta al final de la representación:
"Poulenc és un músic talentós, però sembla que esmerça deplorablement les seves facultats. En la partitura de "Les Biches" hi ha coses ben reeixides; un cert sabor popular força picant $\mathrm{i}$ una vena melòdica fàcil i simpàtica fan agradosos alguns dels seus episodis, però en conjunt ens deixà decebuts. L'efecte còmic musical és perseguit per làutor amb l'aplicació de clixés gastats que han perdut eficàcia. Manca també d'originalitat aquesta música massa despreocupada. Tantes invectives com han pronunciat contra Ravel aquests cridaners sediciosos de darrera hora, i tots acuden a consultar, sense disimular-ho gaire, els rics vocabularis de l'autor de "Dafnis"! A més a més, quan voldrán deixar en pau el "Pulcinella" de Stravinsky. La part vocal ha estat suprimida. La coreografía és molt notable i el artistes russos fan una excellent tasca, sobretot els homes. L'acció del ballet és d'una oportuna vaguetat. Sense això, tot el que tindria el seu marc apropiat en una revista, apareixeria massa fora de lloc en un teatre de les condicions del Liceu". 82

\footnotetext{
79 J. Llongueras, "Els balls russos al Liceu", La Veu de Catalunya, 8 de mayo de 1927, p. 6.

80 El Diluvio, 8 de mayo de 1927, p. 6.

81 "Balls russos", La Publicitat, 10 de mayo de 1925, p. 6.

82 "Liceu. Balls russos", La Publicitat, 12 de mayo de 1927, p. 4.
} 
Por su parte Joan Llongueras en La Veu de Catalunya tampoco valoró de forma muy positiva la música de Poulenc. Se declaraba desorientado ante el insulso espectáculo ofrecido por la compañía de Diaghilev a la que consideraba que se encontraba en pleno declive artístico. ${ }^{83}$ En la misma línea crítica sobre la música de Poulenc se situó la reseña de La Vanguardia. Pero a diferencia de lo escrito en otras crónicas, para este diario la coreografía fue, simplemente, vaciada de contenido. ${ }^{84}$

El jueves 12 de mayo en sesión nocturna se incluyeron dos nuevos estrenos: "Zephir et Flore" y "Romeo y Julieta". Cerró la noche "L'mariage d'Aurore". ${ }^{85}$ Ninguna de las dos novedades presentadas causó gran sensación ni en la crítica ni el público asistente al Liceo como mostró la crónica de la sesión de $B$. de P. en El Correo Catalán:

"En "Romeo y Julieta" ...bailable, la música debida a Constant Lambert tiene bien definido el sentido irónico que imprime carácter a la obra. Pero sólo en contados momentos se sostiene a buena altura. La ejecución escénica, así en lo que respecta a la pantomima, como en el desarrollo de la parte coreográfica, no desmerece de las buenas exhibiciones del teatro ruso bailable. Los artistas fueron, muy aplaudidos. Boris Kochno puso música a los tres cuadres de "Céfiro y Flora", sólo de una manera discreta. La representación de esta obrita tiene algún detalle discutible, por más que la seriedad y alto sentido artístico que es norma de la Compañía Diaghilew., deja siempre a salvo los pormenores del espectáculo. El público no convencióse enteramente, pero, de todos modos no quiso desaprobar estas dos nuevas exhibiciones, y llamó repetidas veces al proscenio a sus intérpretes" ${ }^{86}$

De esta sesión A.M., en el Diario de Barcelona destacó la interpre-

83 J. LL, "Balls Russos de Diaghilew. Les Biches", La Veu de Catalunya, 12 de mayo de 1927, p. 6.

84 "Gran Teatro del Liceo. Los bailes rusos", La Vanguardia, 11 de mayo de 1927, p. 21.

85 La Vanguardia, 12 de mayo de 1927, p. 14.

86 B. de P., "Bailes rusos", El Correo Catalán, 13 de mayo de 1927, p. 5. El crítico en su crónica también señaló el interés de Juan Mestres en la presentación de estrenos en la temporada de bailes rusos, que a su juicio demostraba la voluntad de la empresa en variar los carteles sesiones rusas. Pero por otro lado, advertía que este hecho fuera a costa de "el prurito de la disonancia" y "el recurso demasiado socorrido de la estridencia" para buscar siempre la novedad. 
tación de los bailarines en "Romeo y Julieta" porque con su actuación el espectador se podía olvidar de lo "insípido" de la música y podría distraerse con el decorado de Joan Mirò:

"El argumento de este "ballet" cuya acción tiene lugar durante una lección de danza y ensayo, de los mismos Bailes Rusos, es en síntesis los amoríos de "Danilova" y "Lifar" que los induce a huir en avión después de haber efectuado el ensayo de "Romeo y Julieta" en la sala del teatro. Hay una escena en la que se ve pasar a los danzarines hacia el escenario donde ha de tener efecto el ensayo. Esta escena es sin música $y$, sin embargo, el interés subsiste por la gran expresión que ponen los intérpretes en sus evoluciones y casi diríamos que no sola subsiste el interés, sino que el sentido musical agradece esta pausa" ${ }^{87}$

X., desde las páginas de La Publicitat también mostraba su decepción antes estos dos nuevos estrenos porque no reflejaban lo que se esperaba de la compañía de Diaghilev. Solo destacó, una vez más, la actuación de los bailarines. Se preguntaba entonces el crítico si eran las novedades, por no ser lo esperado por el público, o quizás una producción demasiado moderna para los gustos de los espectadores del Liceo lo que provocó que no disfrutara con la representación:

""Romeo i Julieta" i "Zèfir i Flo$\mathrm{ra}^{\prime \prime}$...aquests dos ballets no han deixat tampoc satisfet l'interès amb què eren esperades les novetat que porten enguany es notables artistes russos. La música del primer és del compositor anglès Constant Lamber, al qual hom no sabria negar, coneguda esta partitura, qualitats molt estimables, però que semblen poc madurades i no ben orientades encara......La música de Duklesky és molt poc interessant, monòtona i poc colorida, plena de vulgaritats i d'un aire tudesc poc escaient al caràcter de l'obra. La tasca dels dansarins en aquet ballet $i$ en l'altre estrenat, fou excelent per tots conceptes. Cal esmentar, sobretot, la senyora Danilova i els senyor Massien i Ligar, admirables tot hora. Les dues obras foren rebudes amb prevenció. Potser ha vingut un xic de nou tot això i el públic no sap divertir-s'hi". ${ }^{88}$

87 A.M., "Bailes Rusos", Diario de Barcelona, 14 de mayo de 1927, p. 6.

88 X., "Liceu. Balls russos", La Publicitat, 15 de mayo de 1927, p. 6. Joan Llongueras en La Veu de Catalunya, reflejó la misma idea de falta de entusiasmo del público ante estos dos estrenos 
Muchas de las demandas de la crítica y público reflejadas en la prensa al inicio de las sesiones de bailes rusos de este año, fueron motivadas por la presentación de unas novedades artísticas que ya no recordaban a lo visto en temporadas anteriores de la compañía de Diaghilev. Es decir, no se ofrecían obras de su "repertorio clásico". ${ }^{89}$ Así que no fue hasta el reestreno en Barcelona de "Petruchka" el sábado 14 de mayo cuando esta demanda pareció ser satisfecha a la vista de parte de la crítica que seguía las evoluciones de los ballets russes. Completaron el cartel otras obras clásicas como "Carnaval" y "Romeo y Julieta":

"Con "Petruchka", la compañía de Sergio Diaghilew se redimía anoche de las culpas de los pasados días, y llevaba de nuevo por sus naturales cauces al "ba"let" ruso... No se puede decir que el tiempo transcurrido entre el estreno de "Petruchka" y la representación de ahora haya atenuado el placer de su audición. La música de Strawinsky, que con soberana fuerza comenta el drama escénico, no ofrece sorpresas de estilo ni de procedimientos... Carnaval, vieja historia de amores entre máscaras y lindas mujercitas; admirables escenas, compuestas por Fokine sobre la romántica música de Schumann, con hondo sentimiento del arte, figuraba también en el programa de anoche. La interpretación no mejoró otras anteriores: pero fué más que discreta, y sostuvo vivos el interés y el alto valor del artístico espectáculo". 90

En la misma línea crítica Joan Llongueras calificó los ballets "Petrouchka" y "Carnaval" como de los que más éxito han tenido siempre convirtiéndose en "indispensables" dentro del amplio conjunto de producciones de Diaghilev. De "Carnaval", Llongueras creía que su popularidad venía marcada por su carácter romántico y por lo conocida que era su música. Sin embargo, "Petrouchka", calificada como uno de los grandes aciertos de Stravinsky por el crítico de La Veu de Catalunya, la consideraba un modelo dentro del mundo de la danza y una de las obras que más fama le habían dado a los Ballets Russes:

"Petrouchka, és i derà sempre un dels grans encerts de Strawinsky. La música aquesta té un caràcter formidable $\mathrm{i}$ té riquesa de color i té exuberància de vida. Cada personatge

de la noche, en cambio la última obra de la programación, "L'mariage d'Aurore", si que recibió "la comprensió del públic en general", J. Llongueras, "Balls Russos al Liceu", La Veu de Catalunya, 13 de mayo de 1927, p. 6. 
és en ella admirablemente carcateritzat i cada escena magistrament descrita. L'assumpte és una vertibale troballa. L'interès de l'obra no decau un sol momento i el tràgic desenllaç amb la mort de "Petrouchka", víctima de la vida que li ha donat el nigromàntic $a m b$ sa màgia $i$ les cruels increpacions que, per damunt la barraca, dirigeix el pobre putxinelli al seu fatal animador, produexien sempre una fona emoció i una forta esgarrifança. ${ }^{\prime \prime 1}$

\section{El 15 de mayo de 1927 a las 17:15} horas en la segunda sesión de tarde de la temporada se programaron "La boutique fantastique", "Le mariage d'Aurore" y las danzas de "El príncipe Igor". ${ }^{92}$ El 17 de mayo de 1927 se celebró en el Liceo la gala del XXV aniversario de la coronación del Rey Alfonso XIII' ${ }^{93}$ dentro de los actos que se venían celebrando durante este día y los sucesivos tanto en Madrid como en Barcelona por la efeméride real. ${ }^{94}$ El programa de la noche se configuró con "Petrouchka", "El sombrero de tres picos" y las danzas de "El príncipe lgor" donde Massine cuajó una gran actuación y el público aplaudió mucho todas las actuaciones:

"La tasca dels artistes russos en aquests ballets ha estat d'un extraordinari relleu. Dins el conjunt, admirable sempre, ha destacat especialment el senyor Massine, que ha fet un "Petrutxka" incomparable, i, en la suculenta obra de Falla,

89 La crítica se refería a obras, sobre todo de Stravinksy u otras que tuvieron gran éxito en su primera etapa en Barcelona.

90 Z.,"Gran Teatro del Liceo. Petruchka", La Vanguardia, 15 de mayo de 1927, p. 23.

91 J. LL., "Gran Teatre del Liceu. Balls Russos de Diaghilew", La Veu de Catalunya, 15 de mayo de 1927, p. 8.

92 La Publicitat, 17 de mayo de 1925, p. 11. Programa de manos de la sesión del 15 de mayo de 1927. BNF, département Bibliothèque-musée de l'Opéra, AID-931 (6, 258-293) [https:// gallica.bnf.fr/ark:/12148/btv1b8419216p].

93 La Publicitat, 17 de mayo de 1927, p. 9.

94 El Diario de Barcelona, por ejemplo, dedica sus primeras 14 páginas a noticias sobre la efemerides real, destacando desde notas de prensa de 1902 cuando fue nombrado Rey hasta todas las celebraciones que se iban a dar sobre todo en Barcelona, pero también en Madrid y en otras provincias de España. Aunque también informa sobre celebraciones en ciudades fuera de España como Buenos Aires o Berlín. Diario de Barcelona, 17 de mayo de 1927, pp. 1-14. Los días 18 y 19 el Diario de Barcelona continuaba con las informaciones sobre los actos ya celebrados reservados a las primeras páginas. Ver crónica completa de la sesión en Z., "Gran Teatro del Liceo. El sombrero de tres picos", La Vanguardia, 18 de mayo de 1927, p. 10. 
un "Moliner" prodigiós. Es tot el ballet las seva actuació és $d^{\prime}$ un interès excepcional: però la seva gran dansa, en particular -episodi dels més reeïxits de l'obra- és tod un poema. El públic ha celebrat molt i aplaudit unànimement aquestes representacions". ${ }^{95}$

El miércoles 18 en horario nocturno los ballets russes representaron por primera vez esta temporada "Cimarosiana" y "Las mujeres del buen humor". Cerraba el programa "El sombrero de tres picos" con gran triunfo entre el público. Llongueras, en su crítica de la sesión introdujo una larga reflexión tras observar la coreografía cuasi-estática de los bailarines en "Las mujeres del buen humor", que contrastaba con la música alegre de Scarlattí. Se preguntaba por la importancia de la música en los distintos componentes técnicos de la danza, y de cómo los bailarines de Diaghilev no llegaron a desarrollar una sensibilidad musical acorde con sus movimientos en la representación artística de este arte. A raíz de este argumento creía necesario crear un "contrapunt plàstic-corporal per damunt de la música", es decir, ir más allá de la música en la función estética de la danza:
"Quan per la dansa, avui día, se demana la cooperación de la música no és prou que la dansa sía una pantomima, una estilització més o menys ben sentida, un joc convencional, una nota de color, un divertiment pels ulls, caldía també que aquesta dansa ultra tot això tingués també una essencial indispensable valor de musicalitat. LLavors els moviments de dansa trobarien matisos i detalls d'expressió i d'emoció viva del tot insospitable ara i la dansa es trobaría infinitament enriquida. Els qui, amb ulls de pintor o amb fantasies de literat s'entusiasmaren davant d'algun dels ballets nous que han estat donats enguany, es deixaren enlluernar per la visió anecdótica i no s'adonaren que gairebé sempre la música era una monótona i molt pobra de plasticitat i que en els moviments aquells, de tan aguda $i$ atrevida estilització, mancava per complet la sensibilitat musical que tota veritable i artística realització plàstica ha de tenir indispensablement". ${ }^{96}$

Al día siguiente, jueves 19 de mayo, continuó la programación con, de nuevo, dos estrenos de temporada "Carnaval" y "Thamar"; com-

95 "Liceu. Balls russos", La Publicitat, 19 de mayo de 1927, p. 6.

96 J. LL., "Gran Teatre del Liceu. Balls russos de Diaghilev", La Veu de Catalunya, 19 de mayo de 1927, p. 6. 
pletaron el cartel "Cimarosiana" y las danzas de "El príncipe lgor".97 Joan Llongueras en su crónica en La Veu de Catalunya calificó "Thamar" como poco moderna al encasillarla como un ballet de antes de la guerra. También señaló la falta de interés del público del Liceo durante esta temporada por el espectáculo de los ballets russes de Diaghilev. ${ }^{98}$ El viernes 20 la función estuvo compuesta por "Les femmes de bonne humeur", "Petrouchka" y "El sombrero de tres picos". Era la primera de la tres sesiones de despedida de Barcelona por parte de la compañía de Diaghilev:

"Con las funciones de hoy, viernes, mañana sábado, y domingo, tarde, se despediran de nuestro público los famosos Balltes Rusos en el Gran Teatro del Liceo. No ha sido posible lograr el que dieran unas funciones más tan celebrados artistas moscovitas por tener que debutar en París el próximo martes. Los programas de estas últimas funciones lo constituyen las obras que mayor éxito han alcanzado en Barcelona, siendo el del sábado y el del domingo, por la tarde verdaderamente atractivos". 99

El sábado 21 de mayo en el mismo horario nocturno se programó "El matrimonio de Aurora", "Thamar" y "La boutique fantastique". ${ }^{100} \mathrm{El}$ domingo 22 a las 17:45 horas se celebró la que sería la última sesión de los bailes rusos en el Gran Teatro del Liceo de esta temporada de primavera de 1927 con las representaciones de "Cimarosiana", "Petrouchka" y "El sombrero de tres picos". ${ }^{101}$

Al igual que pasó con el primer estreno de "Les Sylphides", que abrió como novedad la primera sesión en España un 26 de mayo de 1916 en Madrid, los bailes rusos finalizaron sus giras en Barcelona, coincidiendo, al igual que el año de su estreno en España, con los actos conmemorativos de la proclamación como rey de Alfonso XIII. ${ }^{102}$ Quedaba ya

97 La Vanguardia, 19 de mayo de 1927, p. 18.

98 J. LL., "Gran Teatre del Liceu. Balls russos de Diaghilev", La Veu de Catalunya, 20 de mayo de 1927, p. 6.

99 "Despedida de los bailes rusos", Diario de Barcelona, 20 de mayo de 1927, p.13.

100 Fue retransmitida por Radio Barcelona. La Vanguardia, el 21 de mayo de 1927, p. 17.

101 "Gran Teatro del Liceo. Despedida de los Bailes Rusos", La Vanguardia, 24 de mayo de 1927 , p. 25.

102 En el Heraldo de Madrid, del 17 de mayo de 1916, $4^{a}$ edición, en su portada se puede ver la noticia donde describen todos los actos que se celebran ese día con motivo del cumpleaños y al aniversario de su coronación como Rey de España. Por otro lado en el diario $A B C$, del 16 
lejos la expectación artística que causaron sus actuaciones en Madrid y Barcelona durante los años 1916 y 1917 motivadas por la falta de escenarios para actuar en Europa a causa de la Primera Guerra Mundial.

\section{Conclusiones}

Los años de estas últimas giras de la compañía de Diaghilev en Barcelona vinieron marcados, en líneas generales, por la caída de la asistencia de público a las sesiones y la falta de novedades interesantes para los espectadores. Así lo reflejaron la mayoría de críticos artísticos que cubrieron informativamente las funciones de la troupe rusa en el Gran Teatro del Liceo. Quizás la temporada de 1924 fue la que mayor éxito de público tuvo motivada por un lado por la vuelta de los ballets russes y por el estreno de "El sombrero de tres picos". La propia crítica de espectáculos mostró un amplio interés por la obra de Falla y Picasso y reservó grandes espacios para las crónicas en los diferentes diarios. El ballet de inspiración española fue junto "Pulcine"la", los grandes reclamos para el público barcelonés que se congregaba en la sala a disfrutar de un espectáculo que muchas veces no entendió (se hallaba "desorientado al igual que parte de la crítica que no terminó de asimilar las nuevas producciones de Diaghilev. Solo en "El Tricorni", donde el público vio reflejada a una España costumbrista escenificada bajo el prisma cubista de Picasso, se abrió la escenografía al conocimiento del espectador, que en este caso, si intuía que estaba pasando sobre el escenario. No obstante la crítica de espectáculos mantuvo durante cada temporada el anhelo de presenciar novedades en la cartelera de cada año de los ballets russes durante estas tres temporadas en Barcelona. Aunque no siempre se llegaron a cumplir las expectativas de los críticos. En algunos casos como los estrenos de "Les Maletots" o "Les biches", simplemente no se las consideró representaciones propias de la compañía de Diaghilev por no ofrecer el producto cultural que esperaban del empresario ruso. En otros por ejemplo, como fue la presentación del ballet "Le mariage d'Aurora", no fue lo esperado: "¡No es això!". Incluso el propio Joan Llongueras lle-

de mayo de 1916, en su página 15, se puede leer la noticia de la llegada de la compañía de bailes rusos de Diaghilev al puerto de Cádiz. Debutarían en el Teatro Real de Madrid el 26 de mayo de 1916. Se pueden consultar las crónicas del estreno en El Imparcial, 27 de mayo de 1916, p. 2; El Globo, 27 de mayo de 1916, p. 1; Heraldo de Madrid, 27 de mayo de 1916, p. 2.; La Correspondencia de España, 27 de mayo de 1916, p. 3; ABC, 27 de mayo de 1916, p. 17; y El País, 27 de mayo de 1916, p. 3. 
gó a plantear que la compañía había caído en decadencia artística.

Tras las temporadas de 1924 y 1925 la prensa teatral ya demandaba en el año 1927 la vuelta al repertorio denominado por la crítica como el "clásico de los ballets russes". Se refería a obras con música de Stravinsky y algunos ballets de su primera época de antes de la Gran Guerra como "Carnaval". $\mathrm{Si}$ a este hecho se le sumaban las dificultades técnicas en la interpretación musical y la falta de ensayos de los directores con la orquesta de profesores del Liceo. Muchas veces, la parte de las representaciones que correspondía a la música tampoco estaba a la altura respecto del nivel que se le suponía tanto al espectóculo como al escenario donde se representaba. Ni Eugene Goosens ni Edouard Flament pudieron corresponder con la responsabilidad de la dirección musical.

Por otro lado, cabe reseñar el desigual seguimiento que mostraron los diferentes periódicos que cubrieron las funciones de los bailes rusos. Desde resúmenes poco detallados del espectáculo, donde se abusaba de adjetivos sin destacar en análisis centrados en los elementos de la danza y la música, hasta otras crónicas de sesiones más analíticas como las realizadas por Joan Llongueras en La Veu de Catalunya,
" $\mathrm{X}$ " en La Publicitat, y en menor medida "Walter" en La Vanguardia. Parte de esta crítica fue muy minuciosa en la valoración musical de las representaciones de los bailes rusos. En cierto modo, debido a que algunos críticos teatrales ya tenían referencias de antiguas representaciones de las primeras giras de la compañía rusa en Barcelona (años 1917 y 1918). A este hecho se le sumaba que ya se habían escuchado las orquestaciones de algunos ballets de la mano de Pau Casals o el propio lgor Stravinsky en el mismo Liceo ${ }^{103}$ en fechas anteriores a la reaparición de los bailes rusos en la temporada de primavera de 1924. Tras seis años de ausencias de actuaciones en la capital catalana. Sin embargo, a diferencia de lo referido a la vertiente musical del espectáculo, la parte interpretativa fue la que más elogios recibió en la mayoría de los casos por parte de la prensa. Una crítica de espectáculos que reivindico su modernidad muchas veces ante la programación de los bailes rusos, ya desfasadas según su propia visión de las representaciones, pero que tampoco supo entender ni valorar muchas de las propuestas de reciente creación de la empresa de Diaghilev. En cambio los interpretes sí que ocuparon numerosas líneas escritas para destacar ya fuera su belleza, su 
capacidad técnica o su ejecución interpretativa. Woizinovsky, Sokolova, Nijinska, Zverew u otros recogían los elogios de la crítica al día siguiente de sus actuaciones y no eran, sino ellos y el cuerpo de baile quienes despertaban el interés de la prensa y del público como así se puede comprobar en las crónicas periodísticas de las sesiones.

Por último, la compañía en el año 1925 también vivió los nuevos avatares de los tiempos donde por un lado fue por primera vez las actuaciones de la compañía retransmitidas a través de la onda de Radio Barcelona en directo desde el Liceo y por otro, protagonizó la función homenaje al FC Barcelona por sus éxitos deportivos en un curioso programa mixto. Sobre la inclusión de las retransmisiones de la radio en conciertos y espectáculos como en el caso de los ballets russes, hubieron quejas de algunos empresarios teatrales en lo que se denominó "la crisis del teatro". Si bien los empresarios pudieron culpar a una falta de público en sus programaciones a estas retransmisiones, críticos como Alard defendieron las emisiones en directo a través de las estaciones de radio como medio para subir la popularidad de algunos espectáculos o autores. $^{104}$
Tras la muerte de Diaghilev en agosto de 1929, dos años después de su última visita a Barcelona, la compañía de ballets russes de Diaghilev desapareció como proyecto empresarial. No fue hasta unos años más tarde cuando de la mano de W. Basil y Massine se retomaría el proyecto de una gran compañía de ballet siguiendo la estela dejada por el empresario de San Petersburgo. Así un 4 de mayo de 1935 volverían los ballets russes a Barcelona con el nombre de Bailes rusos de Montecarlo. Abrieron el día de su reaparición con el ballet "Les Silfides", como venía siendo costumbre en la compañía de Diaghilev en su primer día de función, completaron el programa las obras "Le Bal" (se estrenaba en Barcelona), "Los presagios" y "El Danubio azul". ${ }^{105}$

\section{BiblioteCAS, ARCHIVOS Y CENTROS DE DOCUMENTACIÓN}

Arxiu de Revistes Catalanes Antigues (ARCA).

Arxiu Históric de la Societat del Gran Teatre del Liceu.

Arxiu Municipal Contemporaní de Barcelona.

Centre de Documentació i Museu de les Arts Escèniques de la Diputació de Barcelona.

104 Incluso afirmaba que en las retransmisiones desde el Liceo se podían apreciar "gran claridad en los amalgamas de los timbres orquestales", suponía por la instalación de nuevos micrófonos. Alard, "Las emisiones de Radio Barcelona", El Diluvio, 13 de mayo de 1925, p. 16.

105 El Diluvio, 4 de mayo de 1935, p. 2. 
www.gallica.bnf.fr.

www.bne.es

\section{FUENTES IMPRESAS}

$A B C$

El Correo Catalán

La Correspondencia de España

La Época

Diario de Barcelona

El Diluvio

El Globo

Heraldo de Madrid

El Imparcial

El País

La Publicitat

La Vanguardia

La Veu de Catalunya

La Voz de Guipuzcoa

\section{Biblografía}

BUCKLE, Richard (1978), Diaghilev: costumes and designs of $\mathrm{Ba}$ llets, The Metropolitan Musemum of Art, Nueva York.

BUCKLE, Richard (1984), Diaghilev, Hamish Hamilton, Londres.

CASTILLO, Pedro (2017), Crónicas españolas de los bailes rusos de Dia- ghilev (1916-1927), Tesis Doctoral, Universitat Jaume I de Castelló.

GARAFOLA, Lynn (1998), Diaghilev's ballets russes, Da Capo Press, Boston. GARITAONAINDIA, Carmelo (1988). La radio en España (1924-1939), Madrid, Siglo XXI.

GRIGORIEV, Serge L. (1960), The Diaghilev Ballet, 1909-1929, Penguin Books, Harmondsworth, 1960. GRIS, Juan, "Correspondencia y Escritos", ed. $M^{a}$ Dolores Jiménez Blanco, El Acantilado, Barcelona, 2008.

HESS, Carol (2002), Manuel de Falla and the modernism in Spain (1898-1936), Chicago University Press, Chicago.

SALAÜN, Serge y SERRANO, Carlos (eds.) (2007), Los felices años veinte: España, crisis y modernidad, Marcial Pons, Madrid.

SOKOLOVA, Lydia (1960), Dancing for Diaghilev, ed. Richard Buckle, John Murray Publ., Londres.

THARRATS, Joan-Josep (1982), Picasso $i$ el pintors catalans en el baIlet, Edicions del Cotal, Barcelona. 